Mitteilungen der Österreichischen Geographischen Gesellschaft, 161. Jg., S. 271-290

(Annals of the Austrian Geographical Society, Vol. 161, pp. 271-290)

Wien (Vienna) 2019, https://doi.org/10.1553/moegg161s271

\title{
GEOINFORMATION
}

GEOGRAPHIC INFORMATION SCIENCE

\section{Detecting Hot Spots on High Resolution Airborne Thermal Imagery - An Automatic Process to IMPROVE ROOF HeAT LOSS DETECTION}

\author{
Christian BAUER, Katharina KERn, Wolfgang SulzER, all Graz* \\ Initial submission / erste Einreichung: 06/2019; revised submission / revidierte Fassung: 12/2019; \\ final acceptance / endgültige Annahme: 12/2019 \\ with 6 figures and 1 table in the text
}

\section{CONTENTS}

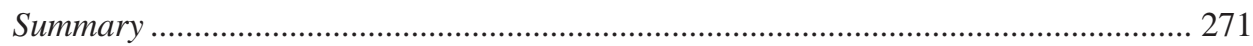

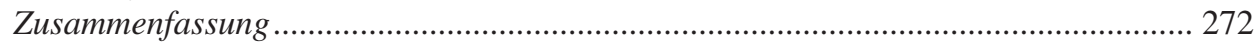

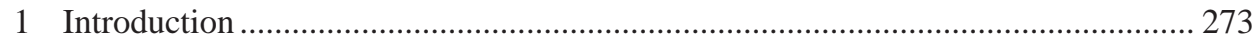

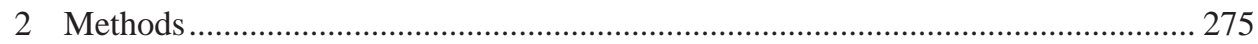

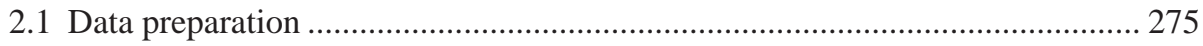

2.2 Extraction of building envelopes and classification of the roofing materials.... 277

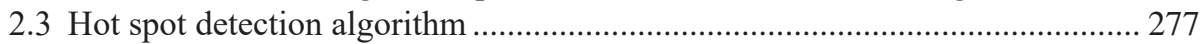

2.4 Model calibration........................................................................................... 280

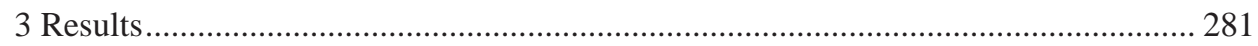

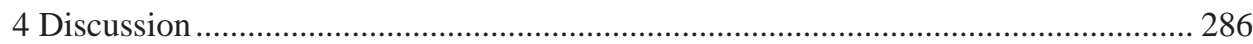

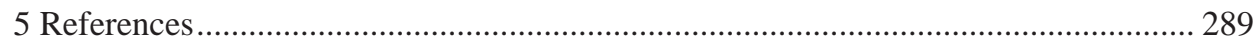

\section{Summary}

This paper focuses on the automatic detection of hot spots on heterogenic roofscapes in high resolution airborne thermal imagery. Previous approaches to detect hot spots

\footnotetext{
* Mag. Dr. Christian Bauer, Mag. Dr. Katharina Kern MBA, Ao. Univ.-Prof. Mag. Dr. Wolfgang Sulzer, all Graz, Department of Geography and Regional Science, University of Graz, Heinrichstraße 36, A-8010 Graz, Austria. Emails: christian.bauer@uni-graz.at, katharina.kern@uni-graz.at,wolfgang.sulzer@uni-graz.at
} 
required either emissivity corrected TIR-data or are only applicable to roofscapes with uniform roof materials. Here we present an automatic detection process using TIR-data without emissivity correction. To achieve this, every single roof and every roof material in the study area has to be acquired from remotely sensed imagery. This is obtained by using an object-based image classification approach based on orthophotos (RGB / IR) with sub-meter spatial resolution and a digital surface model. The hot spot detection is based on a two-step statistical criterion for every previously detected roof envelopes and roofing material. Firstly, the hottest spots on a roof are located by using a peak detection and secondly, a focal neighbourhood function is used to delimit thermal anomalies. The developed method was applied to TIR-data from the Thermal Airborne Broadband Imager (TABI-1800) with a spatial resolution of $0.6 \mathrm{~m} \times 0.6 \mathrm{~m}$. The results demonstrate that the developed method is applicable for heterogenic roofscapes, whereas the detection process highly depends on the roofscape complexity.

Keywords: Airborne thermal imagery, TABI-1800, roof heat loss detection, hot spots, object based classification

\section{Zusammenfassung}

\section{DeteKTION THERMALER ANOMALIEN AUF DACHFLÄCHEN - EIN AUTOMATI- SIERTES, FERNERKUNDUNGSGESTÜTZTES VERFAHREN ZUR VERBESSERUNG DER WÄRMEVERLUSTANALYSE MITTELS HOCHAUFLÖSENDER INFRAROT- THERMOGRAPHIE}

In diesem Beitrag wird eine automatische Detektion thermaler Anomalien (Hot Spots) in heterogenen Dachlandschaften (vor allem Dacheindeckungen) auf Basis von hochauflösenden, flugzeuggetragenen Thermal-Daten präsentiert. Bisherige Ansätze benötigen dafür eine vorgeschaltete Emissionsgradkorrektur der Thermaldaten bzw. können nur in Gebieten homogener Dacheindeckung angewandt werden. Basierend auf einer exakten Ableitung von Flächen gleicher Dacheindeckungsmaterialien zeigt die Methode eine Möglichkeit der Hot Spot Detektion ohne diese vorgeschaltete Emissionsgradkorrektur. Für die Abgrenzung von unterschiedlichen Dachflächen- und Dacheindeckungsmaterialien kam dabei ein objektbasierter Bildanalyse-Ansatz auf Basis eines hochaufösenden Orthophotos (RGB / IR) und Oberflächenmodells zum Einsatz. Die eigentliche Detektion der Hot Spots in den Thermaldaten erfolgte einerseits durch Identifizierung jener Bereiche, deren Temperaturwerte höher sind als alle den Bereich umgebenden, und zweitens durch eine Nachbarschaftsanalyse, wobei die zuvor abgeleiteten Dachfächen gleichen Materials als Begrenzungsflächen für die Nachbarschaftsanalyse herangezogen wurden. Die entwickelte Methode wurde auf Thermal-Daten des Thermal Airborne Broadband Imager (TABI-1800) mit einer räumlichen Auflösung von 0.6m x 0.6m angewandt. Die Ergebnisse zeigen die Eignung der Methode auf sehr heterogenen Dachlandschaften, aber auch den starken Einfluss komplexer Dachlandschaftsstrukturen auf den Detektionsprozess. 


\begin{abstract}
Schlagwörter: Automatische Detektion thermaler Anomalien, flugzeuggetragene Infrarotthermographie, Wärmeverlustanalyse, TABI-1800, objektbasierte Klassifikation
\end{abstract}

\title{
1 Introduction
}

Since urban energy efficiency has become increasingly important over the last years, airborne infrared thermal imagery of buildings and infrastructure are commonly used by public authorities in Northern America and Europe to run energy awareness-raising campaigns and to detect leakages on roofs and building envelopes (e.g. VALENTE et al. 2019; Hemachandran et al. 2018; EnergyCity 2013; Hay et al. 2011; Savelyev and SugumaRAN 2008; ALLINSON 2007). Thereby, false colour representations of thermal images are used to indicate heat loss by visual interpretation. These studies aim to raise the private house owners' awareness to the energy (heat) dissipating from their houses into the atmosphere and subsequently develop and implement energy reduction strategies (e.g. improve the house's roof insulation).

Although thermal imagery provides valuable information about thermal behaviour of roofs, one must consider that a profound interpretation of thermal images is a difficult task (c.f. Vollmer and Möllmann 2011). An initial part in this inspection is the identification of potential leakages in roofs, the so-called hot spots. On thermal infrared images of roofs, hot spots generally do not only represent leakages but all high temperature peaks within the image. For example, in residential buildings they can correspond to roof windows, roof hatches, chimneys or drain waste ventilation pipes and in commercial buildings, hot spots can correspond to air condition and ventilation plants. Hot spots represent all thermal diagnostic features on roofs.

This paper focuses on this initial part of the roof inspection - the detection of hot spots. The most commonly used method for the identification of hot spots and thermal bridges is based only on the visual interpretation of false colour thermal infrared (TIR) images, acquired by thermal infrared cameras or scanners. This implicates several uncertainties. The visual interpretation of TIR images highly depends on the colour range and temperature span that is used to display the data. Small scale roof structures may disappear due to large temperature spans. In contrast, lower temperature spans may exaggerate the appearance of the situation (c.f. VOLLMER and MöLLMANN 2011). The most serious problem by interpreting TIR images arises from the infrared signal itself. The signal recorded by the sensor does not only contain surface temperature information. It is also influenced by the surface material properties (emissivity), atmospheric conditions (e.g. humidity), the radiation wavelength and other factors (e.g. surface geometry).

Emissivity is the fraction of radiation of a measured object (at a given temperature) compared to the radiation emitted by a blackbody (with the same temperature) (MoroPOULOU et al. 2000). Emissivity values range from close to zero to close to one. In contrast to qualitative analysis, a quantitative analysis of heat loss on roofs requires kinetic temperature values. Hence, the emissivity values of all surfaces in the study area have to be known. Emissivity correction of TIR-data is a major issue in the quantitative analysis 
of thermal images (c.f. Pour et al. 2019). In the case of roofs, the emissivity correction must also consider effects of weathered materials (c.f. clay brick, see Fig. 1b), oxidised surfaces (HoLST 2000), surface structure (e.g. polished or roughened) and surface temperature. Depending on these parameters the emissivity value of any roof material may vary significantly (CouTTs et al. 2016). Especially metals are characterised by high emissivity fluctuations, ranging from 0.02 up to 0.8 (Vollmer and Möllmann 2011). In contrast, non-metallic surfaces, such as concrete or bricks have emissivity values greater than 0.8 (BALARAS and Argiriou 2002). The precise knowledge of the surface emissivity is necessary to avoid significant temperature measurement errors (MADDING 1999). In practice, the conversion from apparent temperatures to kinetic temperature is based on emissivity values reported in literature. The disadvantage here is, that literature emissivity values are (if for the respective surface material and wavelength available at all) extremely scattered and may change by more than 0.7 (Albaticia et al. 2013).

Additionally, the roofscapes in Graz are in general very heterogeneous. In most urban districts, it is not possible to determine one dominant roof cover material. In many cases even on a single roof, different roofing materials (metal and non-metal) are used. Additional complexity arises from small roof flashing elements composed of copper, zinc and lead. These construction elements are mounted on dormers, roof valleys and ridges to protect the roof from water penetration. Assuming only one single emissivity value for a roof will therefore cause large errors in calculating kinetic temperature. To obtain accurate emissivity values, direct in-situ measurements concurrently to the data recording are required. To ensure highest possible accuracy this has to be done for every roof material and for different weathering grades - a very time-consuming and expensive procedure.

To detect hot spots, additional data is required to delineate roofs and the different roof covering types within the TIR image. In this study we used a RGB / IR orthophoto with a spatial resolution of $0.25 \mathrm{~m} \times 0.25 \mathrm{~m}$ to capture different roofing materials. Due to the high complexity of the roofing material in the study area, not all existing materials could be detected with the acquired accuracy. However, even studies using hyperspectral data with high spatial resolution show that the delineation of roofing materials with different weathering grades is a difficult task. Uncertainties in urban land cover classification due to similar spectral signatures are documented for slate, asphalt, and other low reflecting materials (FRANKE et al. 2009). Therefore, roof material classification and obtaining accurate emissivity values are considered as the major limiting factors in calculating kinetic temperatures.

The underlying assumption of roof heat loss detection is, that differences in temperature (thermal anomalies) are interpreted as potential heat flux due to poor or missing roof insulation. An initial part of roof heat loss detection is the localisation of the hottest areas (hot spots) on roofs. We present an automatic GIS-based approach to detect hot spots on roofs. The major advantage of the presented method is that hot spots can be detected on heterogenic roofs without an upstreaming emissivity correction - an achieving improvement in the identification of possible hot spots and thermal bridges. The automatic hot spot detection uses ArcGIS geo-processing tools. To provide easy handling, the scripts are compiled to a tool box. Two test sites were selected to evaluate the hot spot detection tool. Those test sites are located in the surrounding area of the University of Graz (Austria) and represent a great variety of housing types and utilisation (residential buildings and commercial buildings). 


\section{Methods}

We developed a GIS based automatic detection process for hot spots using a TIR image captured by the Canadian built TABI-1800 (Thermal Airborne Broadband Imager) sensor and RGB / IR orthophotos (UltraCam) to derive ancillary data (e.g. roof covering types and object boundaries). The TABI-1800 data used in this study was collected over the city of Graz (Austria) on December 20, 2011, in the early night about 4 to 6 hours after sunset $(08.00 \mathrm{pm}$ to $10.00 \mathrm{pm})$. The sensor acquired data in a spectral range of 3.7 to $4.8 \mu \mathrm{m}$ with a spatial resolution of $0.6 \mathrm{~m} \times 0.6 \mathrm{~m}$ and a thermal resolution of $0.05^{\circ} \mathrm{C}$. For the delineation of the roofs and the classification of the roofing materials a combination of UltraCamX data from summer 2011 and a therefrom derived digital surface model (DSM), both with a spatial resolution of $0.25 \mathrm{~m} \times 0.25 \mathrm{~m}$, were used (SULZER et al. 2016).

\subsection{Data Preparation}

The TIR-data not only contains thermally pure pixels, but also a certain degree of mixed pixels. They are typically located at the edges of the roofs as well as at the edges of different roofing materials.

Figure 1a demonstrates the complex mixing situation, a thermal image with $0.6 \mathrm{~m} \mathrm{x}$ $0.6 \mathrm{~m}$ spatial resolution among the edges of a roof and its possible origin. In the first case, the pixel value represents the average radiant temperature emitted by the roof surface and the heat flux ventilating through the eave (Fig. 1a, position 1). In the second case, the pixel value represents the average radiant temperature emitted by the roof surface and the neighbouring (ground-) surface (Fig. 1a, position 2). Thus, all pixels at the edge of the roof contain mixed temperature value and therefore mixed information of at least two surface materials (in this case brick and tarmac) with different emissivity values. Hence, the temperature of this pixel is not representative for one of the two surfaces.

Differences in temperature, boosted by emissivity effects, are clearly recognisable in Fig. 1b/c. The temperature difference between roofs and streets, and consequently the mixed pixel problem, will arise even after a precise emissivity correction (converting apparent temperature to kinetic temperature by integrating material abilities to emit thermal radiation. In addition, sensor based effects, like FOV (field of view) and line of sight geometry effects as well as target based effects due to 3-D surface structure (e.g. inclined roof surface, flat ground) causing temperature fluctuations may occur (CHRISTEN et al. 2012). The occurrence of such effects always has to be kept in mind, but is out of the scope of this paper. These types of errors along the roof edges can be considered as systematic errors.

Figure 1b/c demonstrates the mixed pixel problem (boundary between tarmac and roof covering) surrounding the roof. It is shown that in this case the warmer apparent radiant temperature of the surrounding (mixed pixel) would be detected as hot spots when a regular automatic hot spot detection approach is used. Therefore, to avoid errors related to mixed pixels at the edge of features, a negative buffer (set to minus $1 \mathrm{~m}$ ) was applied to the vector layer of the building outlines (Fig. 1b/c). 


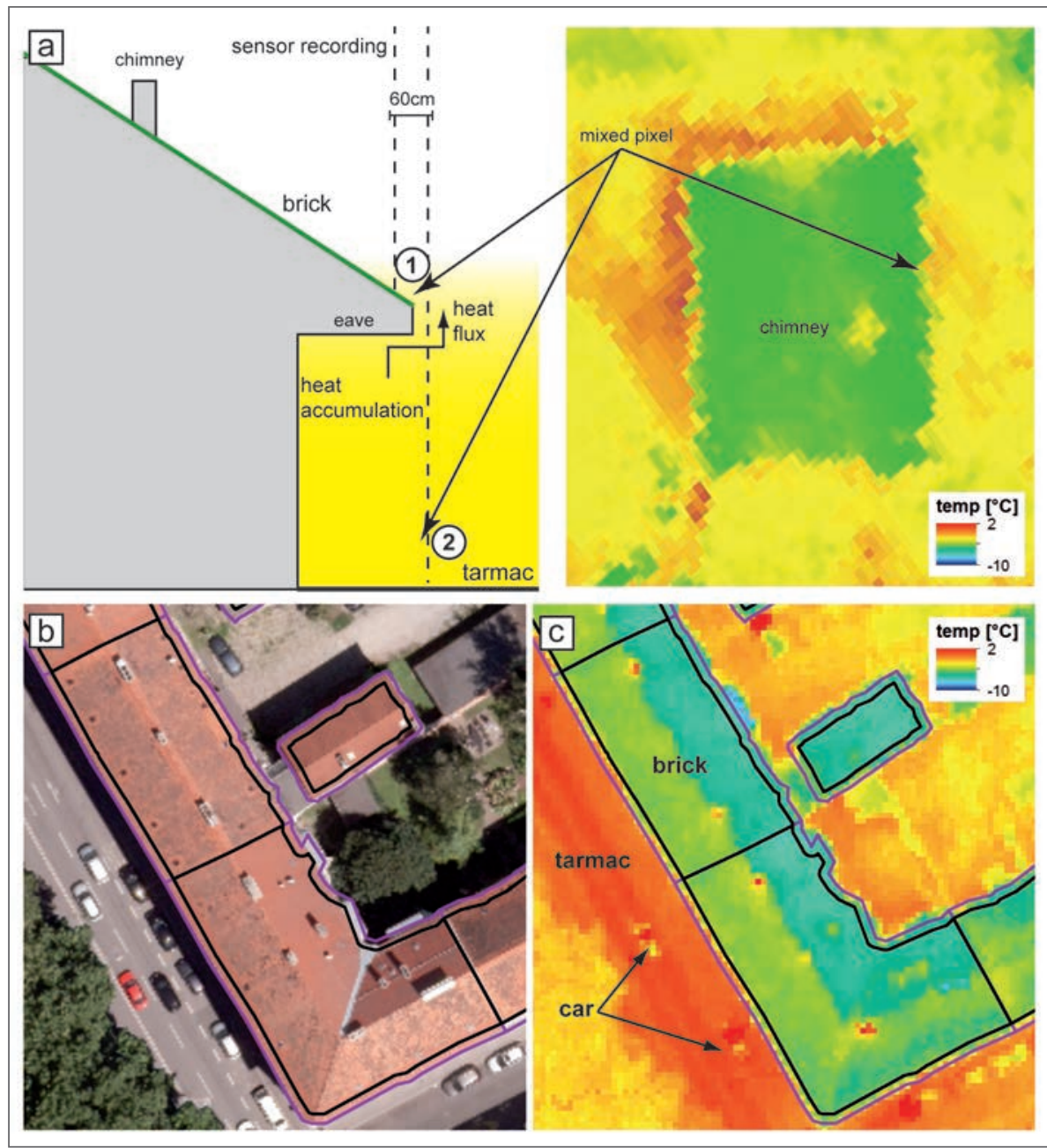

Source: Own calculation and design by the authors

Fig. 1a: Mixed pixel problem illustrated in the TIR image of Graz (TABI 1800, spatial resolution: $0.6 \mathrm{~m} \times 0.6 \mathrm{~m}$; no emissivity correction).

Fig. 1b/c: Automatic building envelope extraction (purple line) and negative buffer (black line).

Fig. 1b: Orthophotograph, UltraCam, spatial resolution: $0.25 \mathrm{~m} \times 0.25 \mathrm{~m}$. The purple line demonstrates a strong visual fit of the automated building envelope extracting process with the RGB image. Visible differences between weathered clay bricks and new roofed clay bricks can be determined.

Fig. 1c: TIR Image (TABI-1800, spatial resolution: $0.6 \mathrm{~m}$ x $0.6 \mathrm{~m}$; no emissivity correction). The buffer distance of minus $1 \mathrm{~m}$ (black line) proved to be adequate to exclude mixed pixels in the hot spot detection process. 


\subsection{Extraction of building envelopes and classification of the roofing materials}

In addition to the roof surface temperature information from the TABI-1800 data, information about all the different roofing materials of each building is needed to perform the hot spot analysis (section 2.3). To extract building envelopes as well as roof covering materials, an object-based image analysis approach (BLASCHKE et al. 2014; PoZNANSKA et al. 2013; TAUBENBÖCK et al. 2013), based on true colour orthophotographs (UltraCam) with sub-meter spatial resolution $(0.25 \mathrm{~m} \times 0.25 \mathrm{~m})$ and a DSM $(0.25 \mathrm{~m} \times 0.25 \mathrm{~m})$ derived from the UltraCam-data, was used (KERN 2015). The latter serves as the primary basis for the delineation of the building outlines.

In the first step, buildings and other elevated objects were derived from the DSM based on height difference information and slope. First results were enhanced by including additional spectral surface information from the orthophotographs into the classification process. Vegetation covered, elevated objects like trees and high bushes could thereby be excluded and the edges of the buildings refined. On the basis of the results from the building delineation all surfaces but roofs could be excluded for the subsequent classification of the roof covering materials beforehand. To classify the different roofing materials a multiresolution segmentation algorithm was used to segment the roofs into objects with a minimum mapping unit (MMU) of $9 \mathrm{~m}^{2}$ and a minimum width of $2 \mathrm{~m}$. The definition of the MMU and the minimum width was necessary due to the spatial resolution of $0.6 \mathrm{~m}$ of the TIR data. Hence, sheet metal installations and other small roof objects like small windows could not be captured as individual roof objects in this study.

In the next step, the roof segments were classified into eight roof material classes (clay tile, fiber cement / slate, metal, cement, gravel / glass and other) on the basis of spectral information of the RGB / IR orthophotographs and surface information from the DSM. Buildings that were part of a block development and covered with the same roofing material could not be automatically detected as individual buildings and needed to be separated manually. The accuracy of the roof material classification differed substantially depending on the type of material. For example, clay tile (with the exception of red painted metal roofs) achieved high classification accuracy. In contrast, fiber cement and slate covered roofs could not be classified in separate classes due to their spectral similarities. In some cases, it was also not possible to separate cement from gravel. Classification problems arose from metal roofs or roof parts, especially red painted metal roofs. This is a particular area of concern, because metals have substantially lower emissivity values than clay tiles. But the use of hyperspectral data for the classification of the roofing material here provides potential for future applications (FrANKE et al. 2009; HeIDEN et al. 2012).

\subsection{Hot Spot Detection Algorithm}

We use a two-step approach, combining a peak detection which is based on hydrological modelling, and a statistical neighbourhood analysis. Two criteria must be met by the cell to be selected as a potential hot spot: (a) a positive identification as a temperature peak and (b) exceeding a certain operating temperature range. Inverse to the common used eight direction 
flow model in hydrologic modeling (JENSON and Domingue 1988), each cell is coded in temperature difference to indicate the number of adjacent cells with lower temperatures. In the case when all eight neighbouring cells show lower temperature values than the processing cell, the processing cell is assigned as a potential hot spot (Fig. 2a). The algorithm neither depends on the magnitude of peak temperature nor on the temperature difference between peak and surrounding cells. Therefore, depending on the complexity of the roof objects (e.g. number of windows, vents or chimneys), the output of this first step contains a large number of extracted features - even though the detected potential hot spots within a distance of minus $1 \mathrm{~m}$ to the building envelope caused by mixed pixel effects have already been excluded.

To enhance interpretation of these potential hot spots, a moving window overlapping neighbourhood focal function was used in the next step. These algorithms are usually used in geomorphologic modelling, like computing terrain characteristics or calculating topographic position indexes (Moore et al. 1991), but became more popular in other GIS analyses (e.g. VIENNEAU et al. 2009) over the last years. The algorithm assigns by cell by cell basis a new value for each processing cell as a function of the associated neighbouring cells. The information about the associated neighbouring cells is obtained by the shape and size of a moving window covering the processing cell and the neighbouring cells. Since neighbourhood identification is overlapping, cells can be assigned multiple times as neighbouring cells. In our case, the moving window has been specified as a circle (Fig. $2 b)$. The larger the moving window is set, the more frequently the neighbourhood statistic criterion is achieved and thus more potential hot spots are assigned as detected hot spots.

In general, hot spots on homogenous material (c.f. roofing cover) contrast with the surrounding cells by a higher digital number (either apparent or kinetic temperature). Thus, hot spots depend on temperature differences with the neighbourhood cells. Problems arise by setting a statistical criterion without operating with true kinetic temperatures to assign a target cell as a hot spot. We calculate the neighbourhood statistic by setting the operator to range (calculation of maximum cell value minus minimum cell value in the predefined neighbourhood). Finally, a threshold value (depending on the radiometric resolution of the TIR data) defines whether a potential hot spot is attributed as detected hot spot or not (Fig. 2c). Therefore, a model calibration (see below) must be carried out for every new TIR dataset. To avoid emissivity problems, we used the ancillary information of the automatically classified building envelopes, subdivided into the dominant roofing materials from the object-based image classification as zonal geometry for the algorithm. Thus, the neighbourhood statistic is calculated for every individual detected roofing material per building envelope.

The greatest advantage of the method mentioned above is its applicability on apparent temperature TIR images. For example: Two roofs with the same kinetic temperature, one covered with roofing tiles, one with a metal roof coverage, do not have the same apparent temperature in the thermal infrared image. Due to the very low emissivity of metal, metal roof coverage appears much colder on uncorrected thermal images than tiled roofs. By setting an absolute temperature threshold value as criterion for the hot spot analysis without a preceding emissivity correction, miscalculations of hot spots on coverage with low emissivity (e.g. metal) are unavoidable (c.f. HEMACHANDRAN 2013). The main steps of the algorithm are illustrated in Figure 2d. All calculations and algorithms are compiled in an ESRI ArcGIS Toolbox giving great flexibility for the application. 


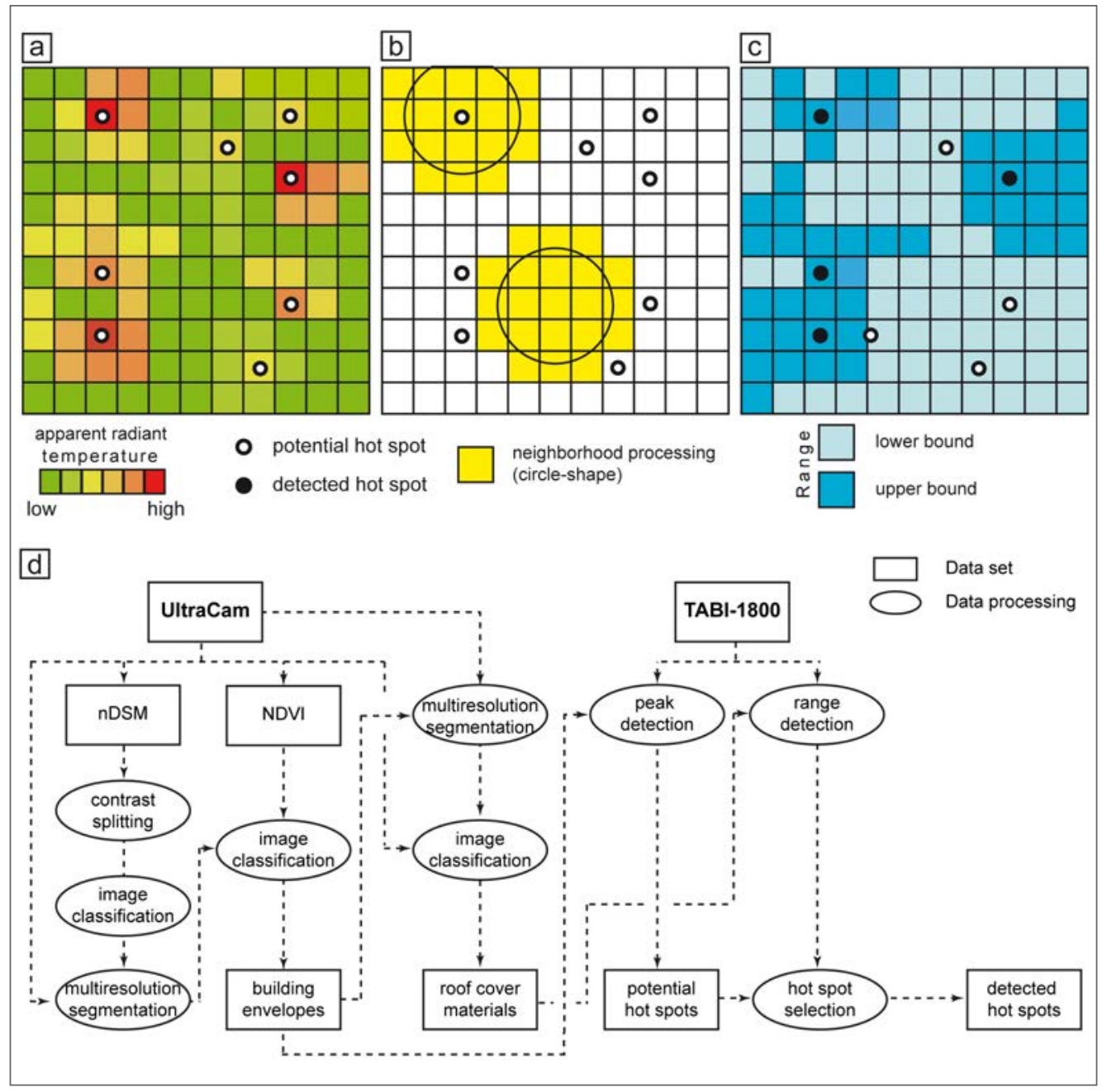

Source: Own design by the authors

Figure 2: Illustration of the hot spot detection procedure

Fig 2a: Temperature peak detection. A cell is assigned as potential hot spot when the digital numbers (apparent temperature) of all eight neighbouring cells show lower values than the processing cell.

Fig 2b: Range detection - neighbourhood processing. The used focal statistic is overlapping.

Fig 2c: Range definition and hot spot selection. Light blue indicates that the digital number of the cell is beneath the defined threshold value. Dark blue indicates that a cell fits the statistical criterion. If both criteria (peak detection and range threshold value) are met, a cell is assigned as a hot spot.

Fig 2d: Flow Diagram of the hot spot detection algorithm. 


\subsection{Model Calibration}

The hot spot detection was calibrated by adjusting the parameters and comparing modelled hot spots with observed data. For this purpose, heat loss areas from remote sensing data were manually detected and mapped. In addition, an in-situ inspection of the roof attic and measurement of thermal anomalies were carried out for selective buildings (Fig. 3). In

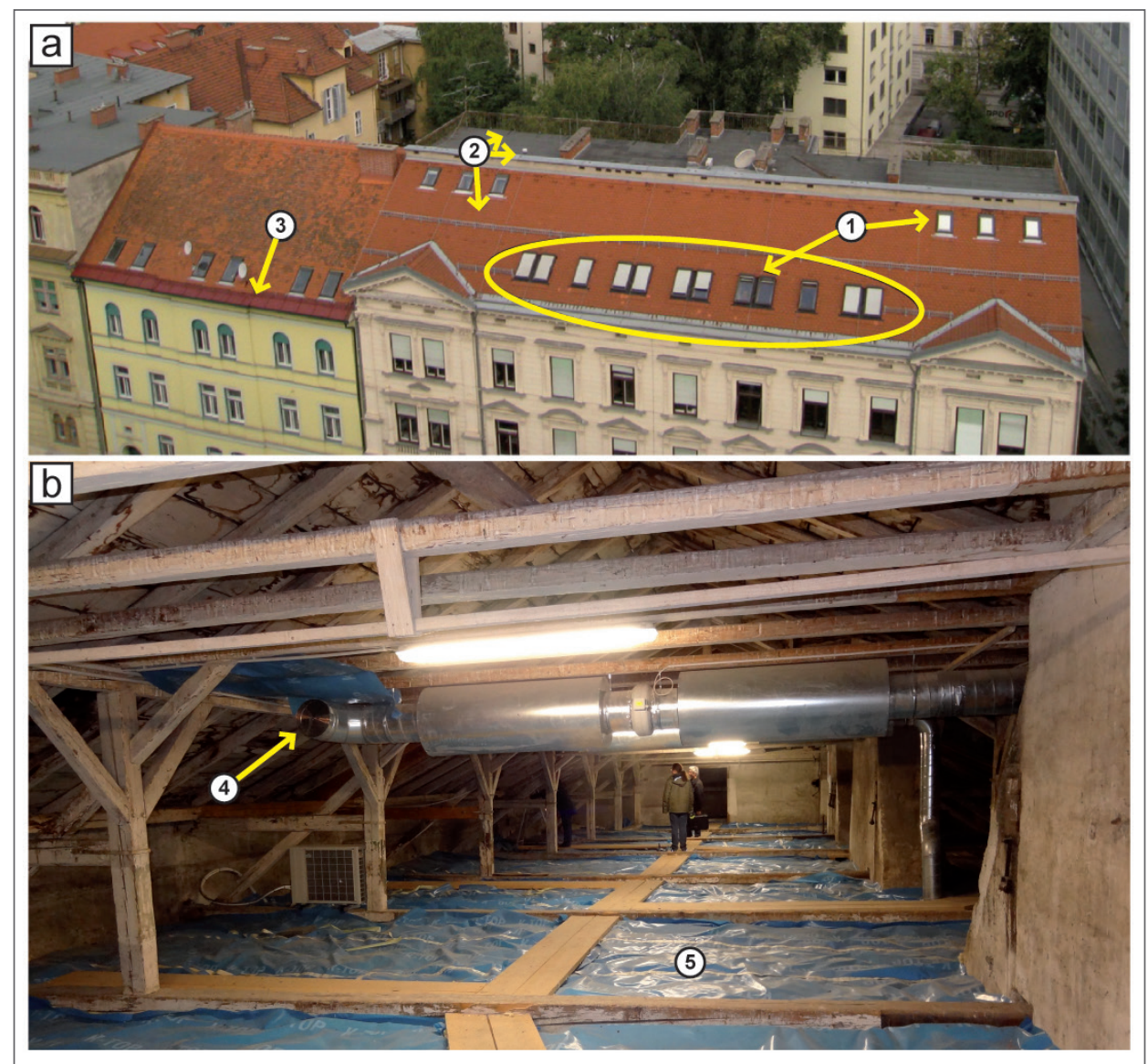

Source: Photos taken by the authors

Figure 3: Model set-up

Fig. 3a: Examples of mapped reference thermal anomalies (position 1). The algorithm was adjusted iterative until almost all reference hot spots were detected. The metal roof installations and small roof flashing elements demonstrating the complexity of heterogenic roof coverings in the study area (positions 2 and 3).

Fig. 3b: In-situ investigation in an insulated roof (position 5). The ventilation pipe is considered as potential thermal anomaly (position 4). 
an iterative procedure, the model parameters (neighbourhood of movable window diameter and range threshold, buffer of the selection) were then adjusted, whereby the observed data served as validation of the modelled hot spots. This calibration process was repeated until the model results matched the reference (observed) data as accurately as possible.

Due to the heterogeneous building structure in the study area, two different model settings have been applied to one single TIR image (one for residential buildings and one for large public or commercial buildings with a high number of ventilation plants). Due to the higher number of potential hot spots on complex roofscapes, the moving search radius must be enlarged on this type of building structures. In comparison, the search radius of the moving window on less complex roof constructions with a small count of hot spots that is typically found on single family detached houses is rather small. The finally used values are shown in Table 1. Depending on the spatial as well as the radiometric resolution of the TIR image, the model parameters have to be adjusted once again.

\begin{tabular}{|c|c|c|c|c|c|}
\hline $\begin{array}{c}\text { Building } \\
\text { structure }\end{array}$ & TIR-Data & $\begin{array}{c}\text { Building } \\
\text { envelope }\end{array}$ & $\begin{array}{c}\text { Roof covering } \\
\text { materials } \\
\text { (classes) }\end{array}$ & $\begin{array}{c}\text { Neighbour- } \\
\text { hood settings }\end{array}$ & $\begin{array}{c}\text { Temperature } \\
\text { threshold } \\
\text { value }\end{array}$ \\
\hline $\begin{array}{c}\text { Residential } \\
\text { building }\end{array}$ & TABI-1800 & $\begin{array}{c}\text { Object based } \\
\text { classification }\end{array}$ & 8 & $\begin{array}{c}\text { Circle; } 2 \text { cell } \\
\text { units }\end{array}$ & $>1.5 \mathrm{~K}$ \\
\hline $\begin{array}{c}\text { Commercial } \\
\text { building }\end{array}$ & TABI-1800 & $\begin{array}{c}\text { Object based } \\
\text { classification }\end{array}$ & 8 & $\begin{array}{c}\text { Circle; } 3 \text { cell } \\
\text { units }\end{array}$ & $>2.0 \mathrm{~K}$ \\
\hline
\end{tabular}

Table 1: Model parameters

\section{Results}

A comparison of the cadastral polygons with the results of the object-based image classification illustrates that the spatial accuracy has been improved. For example, crowns of (high) trees covering building envelopes could be excluded for the hot spot analysis. Furthermore, the required information on roofing cover material can be obtained (Fig. $4 \mathrm{a} / \mathrm{b}$ ). This is of crucial importance as accurate delineated areas of homogeneous roofing materials as zonal geometry is mandatory for the hot spot detection algorithm. The buffer distance of minus $1 \mathrm{~m}$ turned out to be suitable to reduce the mixed pixel problem (Fig. 1c).

The accuracy of the object-based image classification was analysed by using a confusion matrix with 500 automatically generated reference points. The results showed a very good overall classification accuracy of 91.4 percent and a kappa coefficient of 0.88 . The weakest classification results are found in metal roofs. This is mainly due to the fact that metal roofs have very different spectral characteristics, depending on the material, lacquering and weathering. The problem was most obvious with red painted metal roofs that were misclassified as clay tiles. But also gravel and concrete roofs are often difficult to differentiate due to the spectral similarity of the materials.

Two test sites were selected to evaluate the hot spot detection tool. Those test sites are located in the surrounding area of the University of Graz (Fig. 4c, position 2 and 3) and 


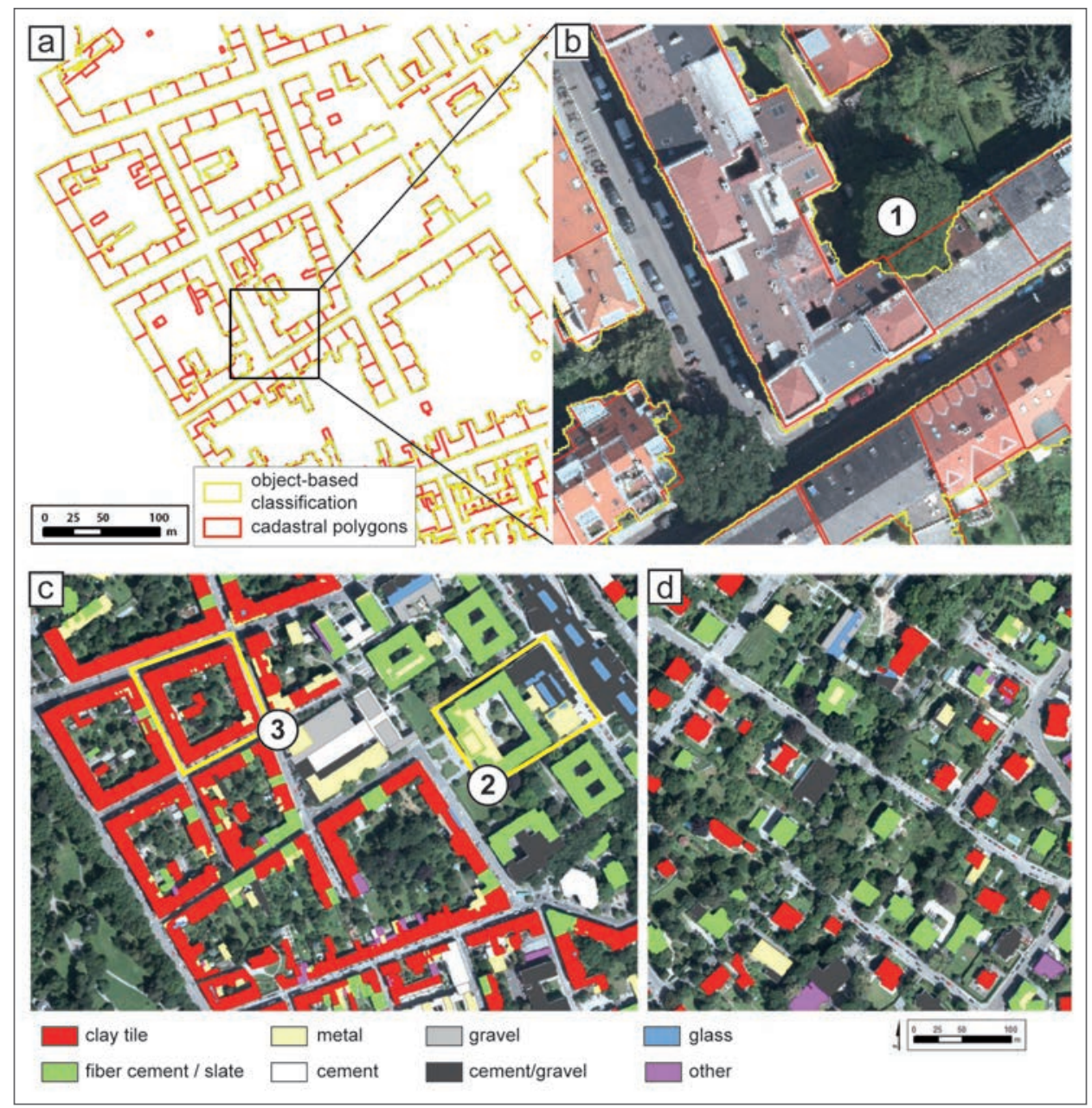

Source: Own calculation and design by the authors

Figure 4: Result of the object-based image classification

Fig. $4 \mathrm{a} / \mathrm{b}$ : Comparison of cadastral polygons and automatic delineated building envelopes.

Fig. 4c/d: Classification of roof covering materials. Position 2 (commercial buildings) and Position 3 (residential buildings) indicate the selected study sites.

represent a great variety of house types and utilisation (residential buildings and commercial buildings).

The type "residential building" is exemplified on a perimeter block development (Fig. 5) from the period of historicism (1840-1900). This type of architecture is typical for the district "Geidorf" in the City of Graz. The floor plan of this type of buildings typically consists of office spaces in the first two floors and residential space in the upper floors. 
In contrast to the orthophotographs, the effects of emissivity on apparent temperature are clearly visible in the TIR image (Fig. 5a/b, position 6 and 7). Due to their very low emissivity, the minimum temperatures on the roofs are associated with metal surfaces (Fig. 5a/b, position 7). Like the neighbouring roofs, the material of position 6 (Fig. $5 \mathrm{a} / \mathrm{b}$ ) consists of clay brick. The sharp delineation on the TIR image (Fig. 5a) indicates rather specific emissivity properties of the roof material than an increased heat transfer. In fact, the interpretation of the thermal behaviour of this roof excluding effects of emissivity is impossible.

The TIR-data of the entire roof in the west appears rather homogeneous. In general, very homogeneous temperature patterns on TIR-data are interpreted as an indication of well insulated roofs (c.f. GuLBE et al. 2017). The result of the detection process demonstrates a strong correlation between the expected (e.g. roof windows, chimneys) hot spot and the modelled hot spots (e.g. Fig. 5a-d, position 1 and 2).

The algorithm depicts every roof window as single hot spot. In spite of double and triple pane windows, roof windows usually indicate critical surfaces for energy loss. Due to neighbouring shadow effects and night sky radiant cooling (VOLLMER and MöLLMANN 2011), windows are "problematic features" on TIR images. In the case of the test site, building heights of the surrounding perimeter blocks are equal and therefore, neighbouring shadow effects can be excluded. The maximum temperatures within the windows are located at the top edge of each roof window (Fig. 5c/d, position 2). One may conclude that these roof windows are displaying rather heat transfer than external influences.

Like the windows, the detection process of hot spots related to chimneys shows a good fitting between the modelled hot spots and TIR-data/orthophotograph (e.g. Fig. 5a-d, position 1 and 2). Due to the large difference in temperature between heated chimneys (c.f. TIR flight mission was taken out in December) and surrounding roofs, chimneys correspond to the hottest features on the roofs. The chimney at position 3 (Fig. 5a-c) demonstrates an error in the peak detection process. The TIR-data indicates a significantly higher temperature in the chimney area compared to the surrounding roof area. But the value of at least one of the eight surrounding cells is equal to the processing cell. Therefore, the algorithm does not exceed the required criteria. Position 4 (Fig. 5a-c) indicates that the chimney was not in service at the time of the thermal survey or it is even abandoned. The latter is not unusual for this type of building structure, since changes from local heating to central heating systems were typically conducted without removing the no longer used chimneys. An accurate delineation of those features (heated chimneys as well as roof windows) provides valuable additional information for inspection and diagnostics of buildings.

Lastly, position 5 (white dots in Fig. 5a/b) indicates hot spot delineation due to mixed pixel problems. As mentioned above these hot spots are finally eliminated by the minus $1 \mathrm{~m}$ building envelope buffer distance.

The second test site is located on the campus of the University of Graz. The complex contains the main building of the University of Graz and the Graz University Library (Fig. $6 \mathrm{a}-\mathrm{c})$. The main building was designed in the style of historicism and houses the auditorium for representational purposes (600 guests) as well as several institutes. The university library is attached to the main building. In 1970 the original library building was enlarged. Nowadays the structure houses a special media department for audio and video materials 
and a catalogue room for online searches. Due to its size and use, the building is also representative for a commercial building.

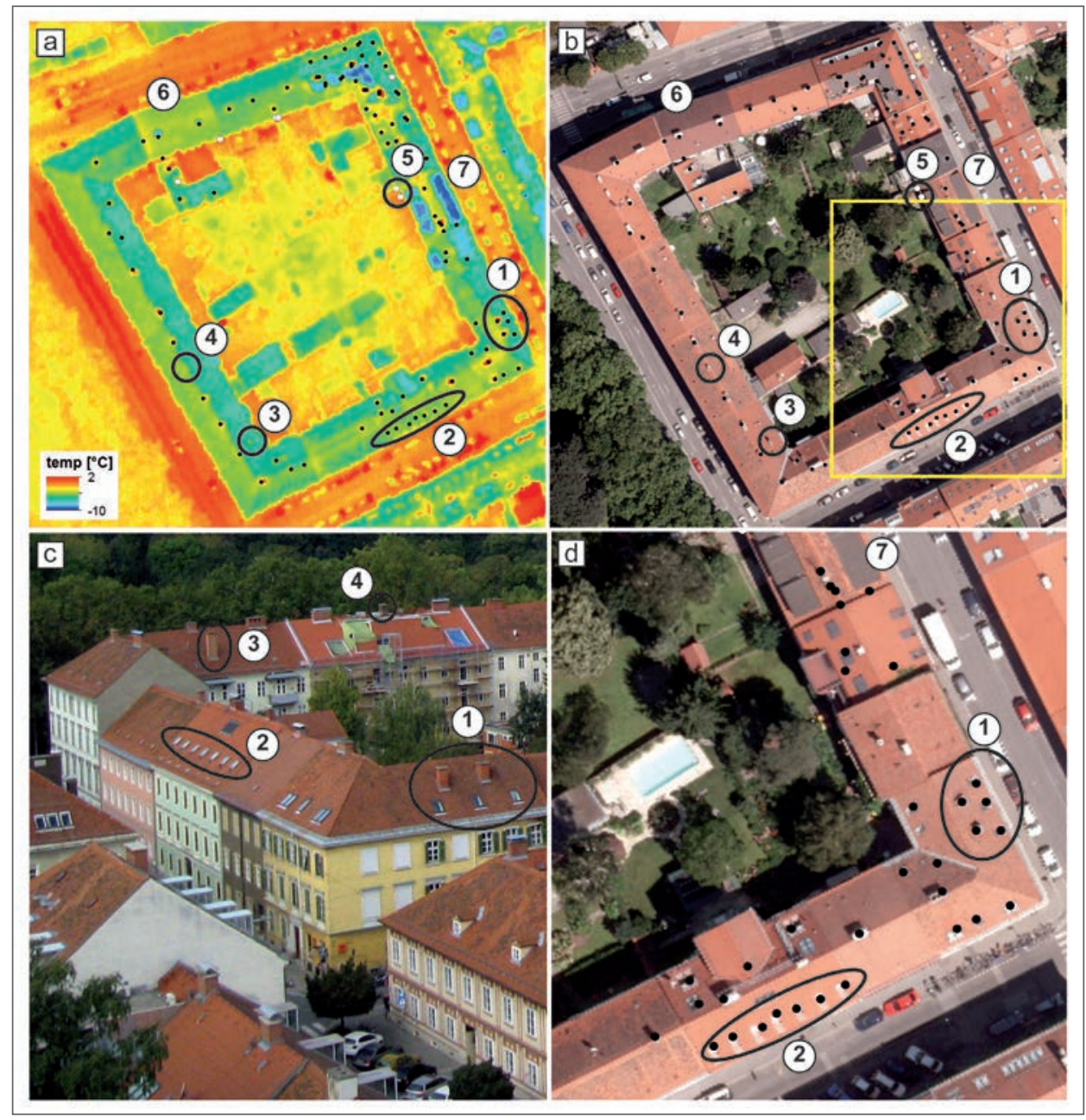

Position 1 and 2 indicate a precise relationship between expected and detected hot spots (chimneys and roof windows). Position 3 and 4: Chimney which does not achieve the required algorithm criteria. Position 5: Example of an excluded hot spot within the minus $1 \mathrm{~m}$ buffer distance of the building envelope.

Figure 5: Hot Spot detection within a perimeter block development

Fig. 5a: TIR image (TABI 1800, spatial resolution: $0.6 \mathrm{~m}$ x $0.6 \mathrm{~m}$; no emissivity correction)

Fig. 5b: Orthophotograph

Fig. 5c: Oblique image, viewing direction $\mathrm{W}$

Fig. 5d: Detail. Black dots indicate detected hot spots. White dots indicate excluded hot spots within the minus $1 \mathrm{~m}$ buffer 


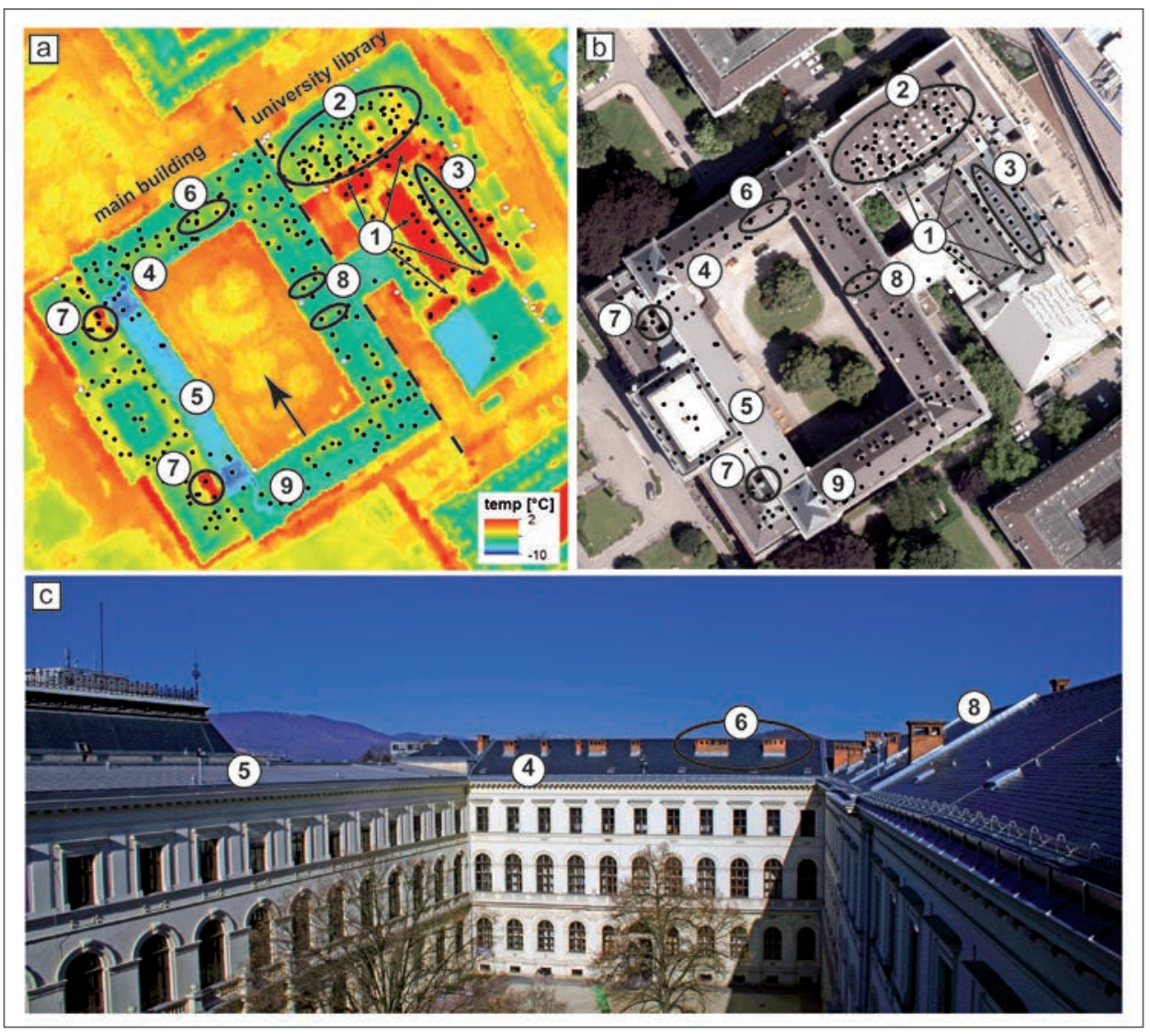

Figure 6: Hot spot detection at the main building of the University of Graz

Fig. 6a: TIR image (TABI 1800, spatial resolution: $0.6 \mathrm{~m} \times 0.6 \mathrm{~m}$; no emissivity correction). The black dashed line marks the structural separation of the main building from the university library. The black arrow indicates the viewing direction of the oblique picture (Fig. 6c). Black dots indicate detected hot spots. White dots indicate excluded hot spots within the minus $1 \mathrm{~m}$ buffer.

Fig. 6b: Orthophotograph, viewing direction NW

Fig. 6c: Oblique picture

In contrast to the residential building mentioned above, the TIR image of this complex appears heterogeneous and reveals remarkable hot areas. Expected thermal bridges on the university library can be found within the glass roof of the main reading room (Fig. $6 \mathrm{a} / \mathrm{b}$, position 1). The single pane windows display poorly insulated areas and heat loss on the image. At least one hot spot on each glass construction is detected.

The top floor of the open-access collections of the library contains many roof windows (Fig. 6a/b, position 2). In this wing, the peak detection delineates a large number of poten- 
tial hot spots. The extensive heat emission of the numerous small roof windows associated with the spatial resolution of $0.6 \mathrm{~m} \times 0.6 \mathrm{~m}$ cause a smoothing effect on the TIR image. Thus, the assigned threshold value is not exceeded here. This makes it rather difficult to assign single hot spots on roofs within complex infrastructure. For that reason, the algorithm has to be modified to get detailed information about potential hot spots of such complex roofs. This can be done by enlarging the radius of the moving search window. However, in this particular case, the geometric resolution of the TIR image was too coarse to delineate every single (small) roof window as single hot spot. An accurate detection of hot spots on such complex roofscapes (e.g. numerous windows) requires very high resolution TIR-data $(<0.5 \mathrm{~m} \mathrm{x}<0.5 \mathrm{~m})$.

Position 3 (Fig. 6a/b) indicates the hot spot detection on an array of roof ventilation plants. These roof installations represent clearly definable features that can be found on many commercial buildings. In the present example, the spatial distance between ventilators is large enough to delineate single ventilators as hot spots at a scale of $0.6 \mathrm{~m} \times 0.6 \mathrm{~m}$ with high accuracy.

The roofscape of the main building of the University of Graz (opened 1895) differs from the complex of the university library. Instead of complex modern roof installations, a large number of chimneys exists on this building. The roof hatches waste ventilation pipes and chimneys (Fig. 6a/b/c, position 6) are correctly detected by the algorithm. Based on apparent temperatures, the hottest position of the main building is situated at unroofed light shafts (Fig. 6a/b, position 7), indicating air movement (heat transfer) through the shaft. The dominant roof materials of the main building are slate tiles (Fig. 6a/b/c, position 4) and, in lesser extent, metal (Fig. 6a/b/c, position 5).

The effects of different emissivity are clearly visible on the thermal image. One may expect linear structures on thermal image due to sheet metal installations in contrast to the surrounding roof coverage (Fig. $6 \mathrm{a} / \mathrm{b} / \mathrm{c}$, position 8 ). Without emissivity correction, metal surfaces appear cooler due to their material properties (c.f. Fig. $6 a / b / c$, position 4 and 5). Interestingly, even on apparent temperature the metal surface at position 8 is displayed as warm.

The algorithm assigns hot spots on each sheet metal installation. Without in-situ investigation, these structures are difficult to interpret. It may be assumed that the metal installation is tracing thermal bridge above the underlying staircase. Such hot spots are considered as point of interests for further investigations regarding waste heat loss.

\section{Discussion}

The presented method to automatically detect hot spots on roofs in TIR (thermal infrared) images uses apparent temperatures only. To assign a cell as a potential hot spot, two criteria must be fulfilled: positive peak detection and achieving the predefined range of temperature within a specified neighbourhood. The settings of the algorithm have to be calibrated to different TIR data and building structures. The perimeter of the moving window and the range threshold value of the neighbourhood analysis strongly depends on the spatial and radiometric resolution of the TIR data as well as on the building structure. The required 
information on building envelopes and especially on roofing cover materials are obtained by applying an image based object classification approach.

We propose two different model settings: one for residential buildings with less complex roof installations, and one for commercial buildings with complex roof installations (c.f. Fig 6. a/b, position 2). The latter is designed to detect more hot spots with high density (e.g. ventilation plants). To avoid errors related to mixed pixels at the edge of the building envelopes, it is suggested to use a negative buffer distance around the features. The distance depends on the spatial resolution of the TIR data and the ancillary building envelope data. In this study a distance of minus $1 \mathrm{~m}$ has been proved to be sufficient to exclude all mixed pixels along the edges. The result of the hot spot detection serves as a basis for subsequent detailed in-situ roof inspections.

The method is applicable to complex building structures with heterogeneous roof coverings that can be found in most European cities - a great advantage of the method. Existing studies and methods were developed in comparatively young cities and buildings with homogenous roof materials. The study of HAY et al. (2011) consists of detached single-unit houses with uniform roof materials (e.g. asphalt shingles). Due to the spatial resolution of the utilised TIR image (1m x 1m), HAY et al. (2011) assume no impact of different surface emissivity (different roofing materials) of objects smaller than $1 \mathrm{~m}$ on the hot spot detection. Therefore without emissivity correction, differences in temperature are interpreted as heat flux. In their approach the hot spot detection is based on the following criteria: The six hottest positions on the roof with a minimum distance of 2-4 pixel ( $1 \mathrm{~m} \times 1 \mathrm{~m}$ resolution) each and the six hottest locations along the building envelope with 1 pixel perimeter.

In contrast to many Northern American cities, the historical development of European cities led to complex building structures and to heterogeneous roofscapes with a great diversity of roof materials. Therefore, some assumptions of the elaborated method from the study of HAY et al. (2011) are not applicable to European cities. In this study a TIR image with $0.6 \mathrm{~m} \times 0.6 \mathrm{~m}$ spatial resolution is used. We point out that emissivity of sheet metal installations has a significant impact on the TIR image. This effect is clearly recognisable on Fig $6 a / b$ (position 9). The v-shaped linear structure, displaying cool temperatures, corresponds to the sheet metal installations on the roof. Considering low emissivity values of metal, this effect is so far not surprising, but it demonstrates the problems in interpreting TIR images of complex roofscapes. Firstly, the spatial resolution of $0.6 \mathrm{~m} \times 0.6 \mathrm{~m}$ is high enough that different emissivity of small scale features on the roof can have an influence on the pixel values of the TIR image. Secondly, the assumption that every temperature change without emissivity correction can be interpreted as heat flux will lead to misinterpretation of the thermal situation of the building. Thirdly, emissivity correction of such small scaled features will prove to be a difficult task. As mentioned above, even with hyperspectral data with high resolution the delineation of these small structures may be impossible. Coming back to Fig 6a/b (position 9): there is no evidence for increased heat flux of the slate roof compared to the metal roof.

Due to the construction and the utilisation of the buildings, the roofscape of the city of Graz can be categorised as thermally complex. For example, a high number of chimneys due to local heating, large window panes, numerous roof windows and ventilation plants on commercial buildings result in a high number of hot spots. Thus, a limitation of the 
maximum number of hot spots (as purposed in the study of HAY et al. 2011)) is not applicable for complex building structures (c.f. Fig. 6a-d).

Heat loss detection based on airborne thermal imagery is still subject to uncertainties. The method presented in this paper is suitable for the initial assessment of TIR images of roofs - the detection of potential hot spots on roofs. Nevertheless, there is a host of limiting factors and errors affecting the analysis:

(a) Although the algorithm is not depending on emissivity corrected data - ancillary information to delineate the different roofing cover materials is necessary. Hot spots at the boundaries of different roofing cover materials cannot be detected precisely due to the mixed pixel effects. The extent of the boundary depends on the spatial resolution of the TIR data; for the TIR-data used in this study $(0.6 \times 0.6 \mathrm{~m})$, a buffer of $1 \mathrm{~m}$ proved to be sufficient. As a consequence, for roofs with a variety of roofing cover materials, large scale areas are excluded from the analysis;

(b) If the roofing cover materials cannot be delineated precisely (e.g. areas < MMU), errors may also occur at their boundaries: large temperature differences due to emissivity properties (e.g. metal and clay bricks) may increase the number of detected hot spots because the defined static criterion of the neighbourhood operation (range) is frequently complied. The radiometric resolution of the UltraCam data used in this study also limits a more distinct differentiation of the roofing materials (e.g. different weathering conditions of clay tiles). This could be improved by using hyperspectral data (which is not available for the city of Graz);

(c) Potential errors also arise from the combination of data sets recorded at different times. For example, the UltraCam data was recorded in July 2011, but the TIR data was recorded in December 2011. A period of six months in dynamically developing cities can already effect major changes (e.g. new constructions, modifications of existing building fabric). This could be improved by recording both thermal and optical data as close to each other (due to the required night flight for TIR-data surveys it is not possible to record them simultaneously);

(d) A challenge of the presented method is the required calibration process. In addition to a manual mapping of hot spots on the TIR data, valid model results also require a set of in-situ inspections of the top attic rooms. In contrast to public buildings, getting access to private buildings is more difficult;

(e) Limiting factors in TIR-data acquisition: (i) High-resolution airborne thermography surveys of entire urban areas require a high number of (overlapping) flight-lines. The data acquisition with the TABI-1800 sensor for the city of Graz (approximately 125 $\mathrm{km}^{2}$ ) has required 20 flight-lines. Radiometric variations between flight-lines often cause errors in the mosaic data-set (this is also valid for the data used in this study). Recently, RAHMAN et al. (2015) demonstrate that these effects can be reduced by a using of relative radiometric normalisation techniques. (ii) Due to Lambert-behaviour of emitting surfaces, radiation measured at the sensor strongly depends on the viewing angle. Maximum radiation is observed from normal direction, oblique direction $>40-45^{\circ}$ leads to declining radiation. The magnitude of this effect is also a function of material (VoLLMER and MöLLMANn 2011). Thus, the impact on remote sensed TIR images depends on (1) viewing geometry, (2) field of view, (3) roof material, (4) roof 
slope, (5) roof exposition, (6) sensor wavelength, (7) temperature (air, surface, sky), (8) atmospheric effects, and (9) sensor calibration.

\section{References}

Albaticia R., Passerinia F., Tonellib A. M., Gialanellac S. (2013): Assessment of the Thermal Emissivity Value of Building Materials Using an Infrared Thermovision Technique Emissometer. In: Energy and Buildings, 66 (1), pp. 33-40.

Allinson D. (2007): Evaluation of Aerial Thermography to Discriminate Loft Insulation in Residential Housing. Doctoral Thesis, University of Nottingham, UK.

Balaras C. A., Argiriou A. A. (2002): Infrared Thermography for Building Diagnostics. In: Energy and Buildings, 34 (2), pp. 171-183.

Blaschke T., Hay G. J., Kelly M., Lang S., Hofmann P., Addink E., Queiroz Feitosa R., van der Meer F., van der Werff H., van Coillie F., Tiede D. (2014): Geographic Object-Based Image Analysis - Towards a New Paradigm. In: ISPRS Journal of Photogrammetry and Remote Sensing, 87, pp. 180-191.

Christen A., Meier F., Scherer D. (2012): High-frequency Fluctuations of Surface Temperatures in an Urban Environment. In: Theoretical and Applied Climatology, 108 (1-2), pp. 301-324.

Coutts A. M., Harris R. J., Phana T., Livesley S. J., Williams N. S. G, Tapper N. J. (2016): Thermal Infrared Remote Sensing of Urban Heat: Hotspots, Vegetation, and an Assessment of Techniques for Use in Urban Planning. In: Remote Sensing of Environment, 186, pp. 637-651.

EnergyCity (2013): Reducing Energy Consumption and $\mathrm{CO}_{2}$ Emissions in Cities across Central Europe. EU Central Europe Program, Final Publication, June 2013. - http://www.energycity2013.eu/media/final-publication_preview.pdf(retrieved: September 2014).

Franke J., Roberts D. A., Halligan K., Menz G. (2009): Hierarchical Multiple Endmember Spectral Mixture Analysis (MESMA) of Hyperspectral Imagery for Urban Environments. In: Remote Sensing of Environment, 113 (8), pp. 1712-1723.

Gulbe L., Caune V., Korats G. (2017): Urban Area Thermal Monitoring: Liepaja Case Study Using Satellite and Aerial Thermal Data. In: International Journal of Applied Earth Observation and Geoinformation, 63, pp. 45-54.

Hay G. J, Kyle C., Hemachandran B., Chen G., Rahman M. M., Fung T. S, Arvai J. L. (2011): Geospatial Technologies to Improve Urban Energy Efficiency. In: Remote Sensing, 3 (7), pp. $1380-1405$.

Heiden U., Heldens W., Roessner S., Segl K., Esch T., Mueller A. (2012): Urban Structure Type Characterisation Using Hyperspectral Remote Sensing and Height Information. In: Landscape and Urban Planning, 105 (4), pp. 361-375.

Hemachandran B., Hay G. J., Rahman M. M., Couloigner I., Zhang Y., Karim B., Fung T. S.,. Kyle, C. D. (2018): Developing Multiscale HEAT Scores from H-Res Airborne Thermal Infrared Imagery to Support Urban Energy Efficiency: Challenges Moving Forward. In: Weng Q., Quattrochi D., Gamba P. E. (Hrsg.): Urban Remote Sensing. Boca Raton: CRC Press, pp. 235-271.

HemachandRan B. (2013): Developing HEAT Scores with H-Res Thermal Imagery to Support Urban Energy Efficiency. Master Thesis, Department of Geography, Calgary, Alberta, Canada.

Holst G. C. (2000): Common Sense Approach to Thermal Imaging. Winter Park, Florida: JCD Publishing / Bellingham, Washington: SPIE Optical Engineering Press. 
Jenson S. K., Domingue J. O. (1988): Extracting Topographic Structure from Digital Elevation Data for Geographic Information System Analysis. In: Photogrammetric Engineering and Remote Sensing, 54 (11), pp. 1593-1600.

KERN K. (2015): Der Einsatz der flugzeuggetragenen Infrarotthermografie zur Erfassung von Wärmeverlusten über Dachflächen - Möglichkeiten und Grenzen der Anwendung. Doctoral Thesis, University of Graz, Austria.

Madding R. P. (1999): Emissivity Measurement and Temperature Correction Accuracy Considerations. In: Lemieux D. H., Snell J. R. (Hrsg.): Proceedings SPIE, Conference vol. 3700: Thermosense XXI, pp. 39-47. - https://doi.org/10.1117/12.342307.

Moore I. D., Grayson R. B., Ladson A. R. (1991): Digital Terrain Modelling: A Review of Hydrological, Geomorphological, and Biological Applications. In: Hydrological Processes, 5 (1), pp. 3-30.

Moropoulou A., Avdelidis N. P., Koui M., Tzevelekos I. (2000): Determination of Emissivity for Building Materials Using Infrared Thermography. In: Thermology International, 10 (3), pp. 115-118.

Pour T., Miřsovský J., Purke,T. (2019): Airborne Thermal Remote Sensing: The Case of the City of Olomouc, Czech Republic. In: European Journal of Remote Sensing, 52 (1), pp. 209-218.

Poznanska A. M., Bayer S., Bucher T. (2013): Derivation of Urban Objects and Their Attributes for Large-scale Urban Areas Based on Very High Resolution UltraCam True Orthophotos and nDSM: A Case Study Berlin, Germany. In: Michel U., Civco D. L., Schulz K., Ehlers M., Nikolakopoulos K. G. (Hrsg.): Proceedings SPIE, Conference vol. 8893: Earth Resources and Environmental Remote Sensing/GIS Applications IV, pp. 301-313. - https:// doi.org/ 10.1117/12.2030000.

Rahman M. M, Hay G .J., Couloigner I., Hemachandran B., Bailin J. (2015): A Comparison of Four Relative Radiometric Normalization (RRN) Techniques for Mosaicing H-res Multi-temporal Thermal Infrared (TIR) Flight-lines of a Complex Urban Scene. In: Journal of Photogrammetry and Remote Sensing, 106, S. 82-94.

Savelyev A., Sugumaran R. (2008): Surface Temperature Mapping of the University of Northern Iowa Campus Using High Resolution Thermal Infrared Aerial Imageries. In: Sensors, 8 (8), pp. 5055-5068.

Sulzer W., Kern K., Bauer C., Lazar R., Mudri M., GANSTER,W. (2016): Fernerkundungsgestütze Wärmeverlustdetektion von Dachflächen als Beitrag zur Energieeffizienzsteigerung von Stadträumen - Ergebnisse einer Fallstudie in Graz/Österreich. In: Schrenk M., Popovic V. V., Zeile P., Elisei P., Beyer. (Hrsg.): REAL CORP 2016 Proceedings/Tagungsband, 22-24 June 2016; pp. 273-285. - https://repository.corp.at/101/1/CORP2016_110.pdf.

Taubenböck H., Klotz M., Wurm M., Schmieder J., Wagner B., Wooster M., Esch T., Dech S. (2013): Delineation of Central Business Districts in Mega City Regions Using Remotely Sensed Data. In: Remote Sensing of Environment, 136, pp. 386-401.

VAlente J., Roldán J. J., GARZÓN M., BARRIEntos A. (2019): Towards Airborne Thermography via Low-Cost Thermopile Infrared Sensors. In: Drones, 3 (30), pp. 1-11.

Vienneau D., De Hoogh K., Briggs D. (2009): A GIS-based Method for Modelling Air Pollution Exposures across Europe. In: Science of the Total Environment, 408 (2), pp. 255-266.

Vollmer M., Möllmann K. P. (2011): Infrared Thermal Imaging. Fundamentals, Research and Applications. Weinheim: Wiley-VCH. 